\title{
Effect of Aluminum Powder additive on Erosion and Bending Resistance of Galvanize Layer
}

\author{
Abbas kamil Othman ${ }^{1} *$ \\ Msc. Metallurgy Engineering. \\ Instructor / Missan University \\ *Corresponding author E-mail: Akoabbbas@Gmail.com
}

\begin{abstract}
Study of the effect of adding aluminum powder to galvanize melt on the microstructure, thickness of the galvanize layer, behavior and nature of fracture in the total layer through the use of optical microscope and scanning electron microscopy. The addition of the aluminum component $(4.5 \%, 5 \%, 5.5 \%)$ to molten is increase the total thickness of the galvanize layer because it increases the thickness of the interlayer and the adhesive layer with the low carbon steel coupled with the increased dipping time in the molten which also increases the thickness of the total galvanize layer. The cracks that were obtained from the bending test were examined for the samples. The samples with the large thickness and the addition ratio (Al-5.5\%) were more resistant to bending. The cracks did not penetrate the surface of the galvanize layer until the angle of bending with the horizon $\left(30^{\circ}\right)$. The erosion resistance was compared to the exposure time of the selection samples, and showed good resistance to erosion at average exposure time. These samples are good in the manufacture of high and medium voltage transmission towers.
\end{abstract}

Keywords: erosion resistance, bending, galvanize layer, cracks

\section{Introduction}

Several studies have dealt with the process of protecting steel from corrosion by using (HOT Dip Galvanize) for its uses in the construction and manufacture of metal structures, columns and towers used in the transmission of electric power. Thus, it is considered one of the most important techniques for protecting steel from corrosion and erosion factors. The galvanize layer produces a zinc-alloy bond with the iron-steel surface with a series of $\mathrm{Zn}-\mathrm{Fe}$ interference medium with the middle and outer layers, usually made up of pure zinc. All these layers form the thickness of the galvanize layer, which is an important and influential factor in the quality engineering standards of coating metals [1,2]. The microstructure and thickness of the galvanize layer are factors affecting the adhesion status of the steel surface and the mechanical behavior of that layer. Therefore, the elements added to the microstructure have an effect on the nature and strength of adhesion directly [3]. The galvanize layer contains three interstitial and overlapping layers that can be observed in Figure (1), starting with the base metal $(\mathrm{Fe}-\alpha),(\delta),(\beta)$ and $(\Gamma)$, which have different mechanical and physical properties[4].

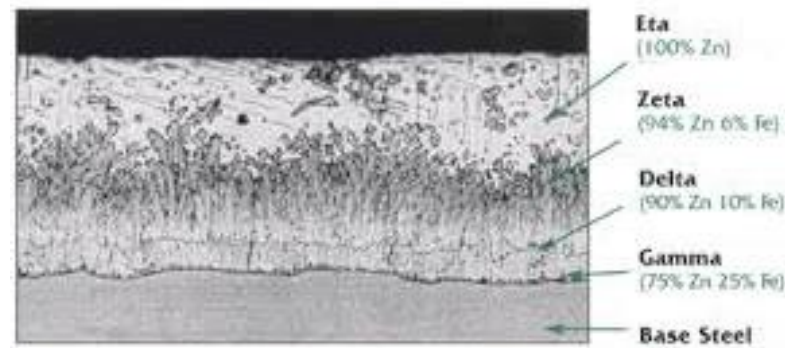

Fig.1: Shows the constituent layers of the galvanize layer

The galvanize layer considers as a cathodic protection pole in some uses as water tanks. The chemical composition both of the zinc molten and steel have a significant effect on the galvanize process[5]. Kinstler presented a study on the microstructure and the added elements and its effect on the thickness of the galvanize layer and the mechanical properties, especially the cracking resistance in the surface of the galvanize layer resulting from freezing. Metal elements in steel, such as $\mathrm{Si}, \mathrm{Mn}, \mathrm{P}$, can accelerate the reaction of $\mathrm{Zn}-\mathrm{Fe}$. Adding elements such as $\mathrm{Cu}$, Tin and $\mathrm{Cd}$ to a zinc-molten bath, with certain proportions, helps increase thickness and change the color of the layer[6]. The study of Sebisty showed the effect of adding (27) element $(1 \%-2 \%)$ separately on the thickness of the galvanize layer, the appearance and the weight and the effect of dipping time in molten [7].the study of Radeker showed that the addition of $\mathrm{Cu}(\mathrm{Pb}, \mathrm{Sn})$ elements by $1 \%$ to $3 \%$ separately increases the diffusion and coverage of molten easily and increases adhesion strength. In the case of copper at $1 \%$ The color of the galvanize layer becomes opaque and increases its resistance to corrosion at $100{ }^{\circ} \mathrm{C}$ [8]. In order to increase the thickness of the galvanize layer, the 
nickel or vanadium element is added, while the bismuth element is added to reduce the thickness of the layer. When cracks occur in the surface of the galvanize layer during solidify, the bismuth and titanium elements accumulates around the crackt and dictate its slot so that the crack area becomes rich of bismuth or titanium [9]. The lead metal $(\mathrm{Pb})$ is found at $0.1 \%$ with some of the elements $\mathrm{Ce}$ and $\mathrm{La}$ (remaining) from the zinc purification process where it is found to increase molten liquidity, which helps to spread the molten on steel surface and reduce the appearance of a brittle internal layer by formed a solid solution (Eutectic) [10]. Increasing the ratio of silicon $(\mathrm{Si})$ in steel by $0.1 \%$ or more has a significant effect on the galvanize process, which reduces the thickness and adhesion strength of the galvanize layer, making it susceptible to breakage under the influence of any bending stress or tensile stress (within elasticity). The silicon $(0.01 \%)$ ratio in the steel increases the thickness of the galvanize layer and the adhesion strength, which increases the breakage resistance [11]. The addition of the aluminum component by $3 \%$ to $4.5 \%$ in the form of small pellets to zinc molten with purity (99.99\%) enables the formation of a ternary alloy ( $\mathrm{Zn}-\mathrm{Fe}-\mathrm{Al})$ Which makes the breakage resistance good under bending effect [12]. In this research, the aluminum component $(4.5 \%, 5 \%$, $5.5 \%$ ) was added in the form of powder and its effect on the thickness of the galvanize layer and its resistance to breakage under bending effect and resistance to the impact of erosion.

\section{Experiments}

\section{Metal}

The low-carbon steel (API-X65) was using by gas and oil industry. Table 1 shows the chemical composition supplied by the manufacturer and is commonly used in the construction of towers used for energy transfer (high and medium voltage ). Two samples of low-carbon steel (API-X65), one without galvanized and the other galvanized with experimental conditions, were prepared in the laboratory of Turkish company (Torsam).

Table.1: Chemical composition of low carbon steel steel (API-X65)

\begin{tabular}{|c|c|c|c|c|c|c|c|c|c|}
\hline $\begin{array}{c}\text { Ele- } \\
\text { ment }\end{array}$ & $\mathrm{C}$ & $\begin{array}{c}\mathrm{M} \\
\mathrm{n}\end{array}$ & $\mathrm{P}$ & $\mathrm{S}$ & $\mathrm{Si}$ & $\begin{array}{c}\mathrm{C} \\
\mathrm{u}\end{array}$ & $\begin{array}{c}\mathrm{Ni}+ \\
\mathrm{Cr} \\
\max \end{array}$ & $\begin{array}{c}\mathrm{Cd}+ \\
\mathrm{V} \\
\max \end{array}$ & $\mathrm{Fe}$ \\
\hline Wt \% & $\begin{array}{c}0.0 \\
8\end{array}$ & $\begin{array}{c}1 . \\
6\end{array}$ & $\begin{array}{c}0.0 \\
2\end{array}$ & $\begin{array}{c}0.00 \\
8\end{array}$ & $\begin{array}{c}0.0 \\
1\end{array}$ & $\begin{array}{c}0 . \\
3\end{array}$ & 0.6 & 0.3 & $\begin{array}{c}\text { bal- } \\
\text { anc }\end{array}$ \\
\hline
\end{tabular}

Hot Dip Galvanize

For the purpose of (H.D.G.) of steel samples, the surface was thoroughly cleaned, degreasing, oil, dust and even the simple rust layer were removed. Use sulfuric acid at $50^{\circ} \mathrm{C}$ for 10 minutes, washed with distilled water and then immersed in a bath of $\left(280 \mathrm{~g} / \mathrm{l} \mathrm{ZnCl}_{2}\right)\left(220 \mathrm{~g} / 1 \mathrm{NH}_{4} \mathrm{Cl}\right)$ at $25^{\circ} \mathrm{C}$ for 2 minutes and then dried with hot air for 10 minutes as shown in Fig. 2. Immersed in HDG with purity $(99.99 \%)$ with metal impurities $(0.01 \%)$ of $(\mathrm{Ce}, \mathrm{La}, \mathrm{Pb})$. Adding powder of $(\mathrm{AL})$ with purity $(99.99 \%)$ and ratios $(4.5 \%, 5 \%$ and $5.5 \%)$ separately in zinc molten, and the samples were dipped in the molten for different periods of time $(15,30,60,120,240,360,600 \mathrm{sec}$.) as shown in figure (2).

device and the speed of the device was set at $25 \mathrm{~m} / \mathrm{min}$. The tests were performed for specific periods of time (5000 Sec, $10000 \mathrm{Sec}, 15000 \mathrm{Sec}, 20000 \mathrm{Sec}, 25000 \mathrm{Sec}, 30000$ Sec),respectively

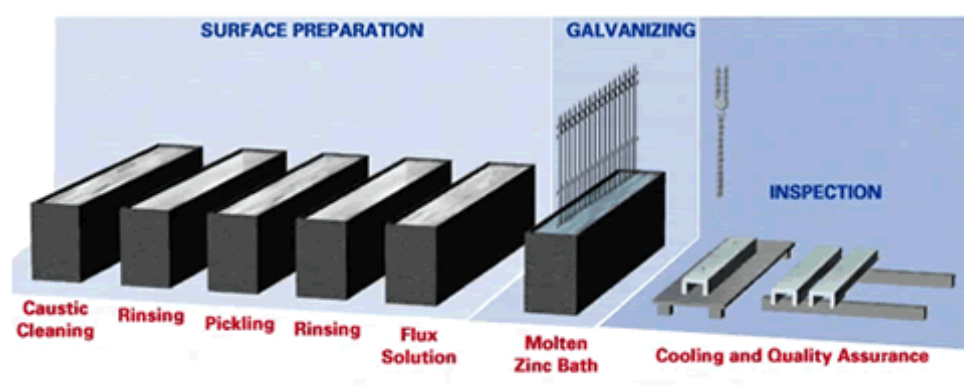

Fig.2: the cycle of the processes in zinc galvanize

Bending test

The samples were prepared according to the geometry required for testing as shown in Fig. 3 and dimensions $(75 \mathrm{~mm}$ length, $12 \mathrm{~mm}$ width). The load was raised from the top. Tests were performed for all types of galvanized samples based on ASTM E 399 and used load cell with capacity (100 Kn) fixed in bending device type (MTS 800), which increases the load gradually and stops manually for the purpose of determining the bending angle at the beginning of the low material resistance directly. The largest displacement of the pull column is $35 \mathrm{~mm}$ to give a bend at an angle of $\left(30^{\circ}\right)$. The bending was tested at angles $\left(0^{\circ}\right.$ $30^{\circ}$ ) and increase gradually with $\left(2^{\circ}\right)$ respectively, and no sample was exposed to the fracture I hope during the test

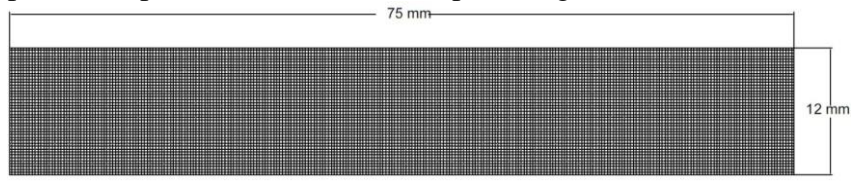

Fig.3: Test sample of bending test

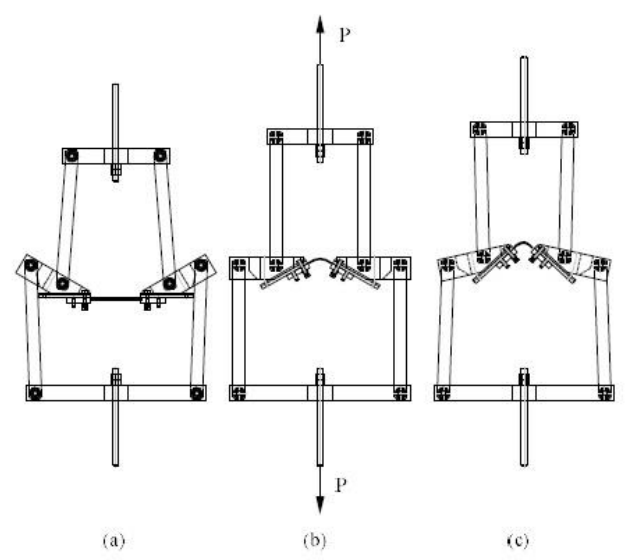

Fig.4: bending test device

Erosion Test

Galvanized samples were prepared at $(4.5 \%, 5 \%, 5.5 \% \mathrm{Al})$ with the dimensions shown in Figure (5) and suitable for installation in the erosion testing apparatus shown in Figure (6). The erosion resistance measured of the galvanize layer was depending to the measurement of hardness (HV). The hardness (HV) of the samples was measured in 15 places in each sample and according to the reading rate to represent the hardness of the sample as shown in Figure (5). Granule sand with a diameter of $2-8 \mathrm{~mm}$ and a density of $1700 \mathrm{Kg} / \mathrm{m} 3$ was used in the erosion testing 

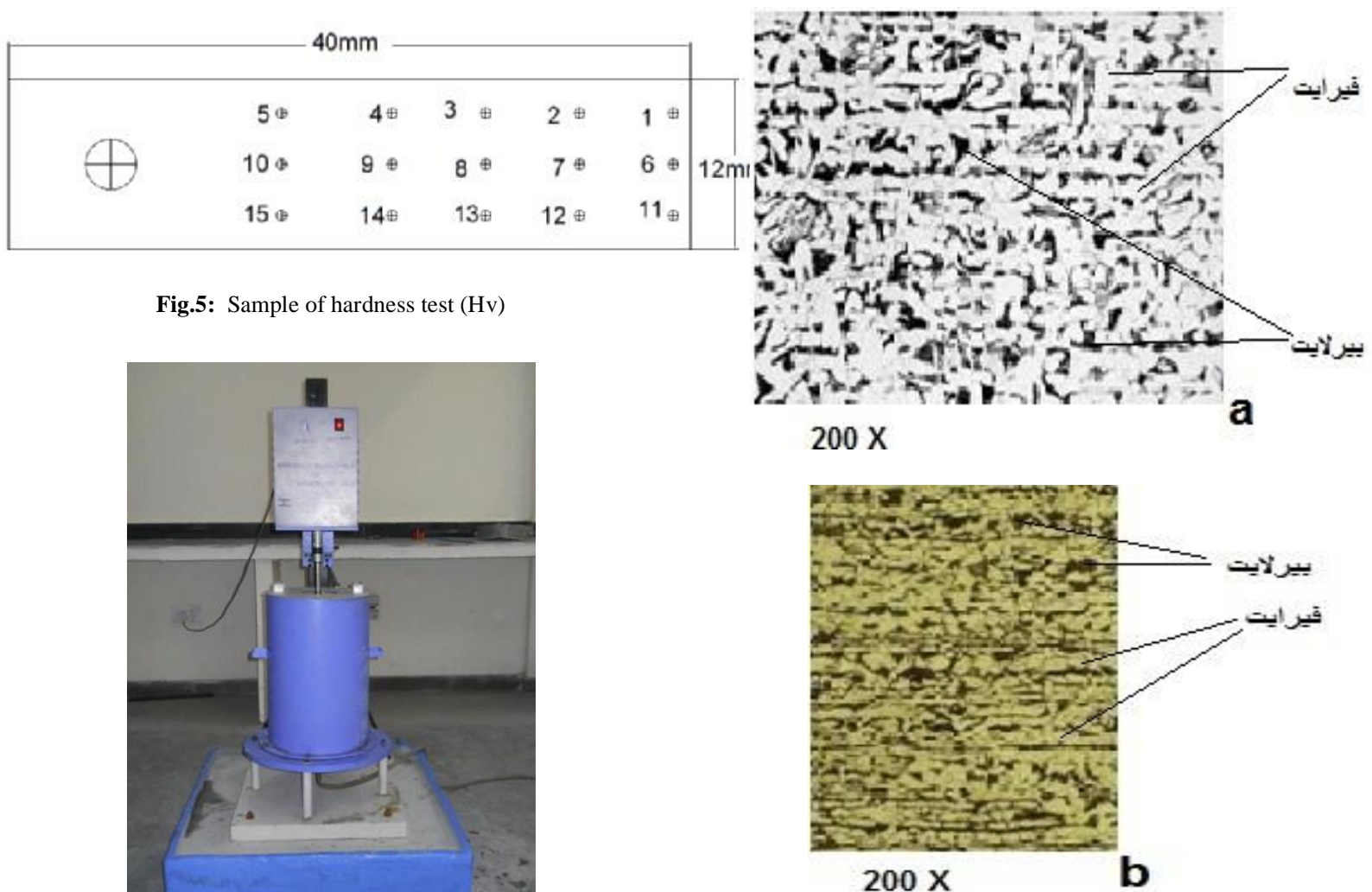

Fig.7.a: shows the microstructure composition of the sample before galvanize process

Fig.6: erosion testing

Fig.7.b: shows the microstructure of the sample after galvanize process

Optical Microscopy (O.M)

Two samples were prepared in a square form $(15 \mathrm{~mm} * 15 \mathrm{~mm})$, one of which is non-galvanized steel and the other is made of galvanized steel with the addition of aluminum. A cross section was prepared for galvanized sample and they were supported by a solid plastic mold and their surfaces were polished to remove the impurities. The samples were polished using a turbopolishing machine (STRUERS TEGRA) with a polishing paper (320 grad) for a minute by adding a liquid of $\mathrm{Al}_{2} \mathrm{O}_{3}$ solution, then using a $(9 \mu \mathrm{m})$ polishing cloth with alumina solution for five minutes and then using a polishing cloth $(3 \mu \mathrm{m})$ with diluted alumina solution with distilled water for four minutes Finally, polished cloth $(1 \mu \mathrm{m})$ with distilled water for a period of one minute and that each refining stage followed by washing samples with distilled water being cleaned and dried well and after polishing process was etching samples with textured ethyl alcohol contains (2\% nitric acid) and were measured the thickness of the layers. The optical microscope (OLYMPUS GX 51) was used to study the microstructure of the steel and the galvanized steel and then measure the thickness of the galvanized layers.

Scanning electron microscopy (SEM)

The galvanized samples tested in bending were prepared and the bending area was only cut and supported with a solid plastic mold for the purpose of examining the cracks and the nature of the breakage in the galvanize layer. The samples that tested with the erosion device were prepared for the purpose of examining the damage caused in the galvanize layer, and for this purpose the scanning electron microscope was used (ASPEX SEM)

\section{Results and Discussion}

Figure [7-a] shows the microstructure composition of the sample before galvanize process which consisting of high density Ferrite phase, longitudinal and transverse diffusion, and perlite phase in the form of longitudinal transverse flakes with different directions. Fig. [7-b] shows the microstructure of the sample after galvanize process which is formed by the ferrite phase as longitudinal strips separated by narrow strips of perlite and this regularity is usually the result of the diffused of some atoms of zinc in the surface of low carbon steel[13].

Figure (8) shows the interstitial phases of the galvanize layer of thickness $(15.4 \mu \mathrm{m})$ which is characterized by different growth dynamics. In $15 \mathrm{Sec}$ of dipping in zinc molten does not affect the thickness of the pure zinc layer adjacent to the steel surface as well as the galvanize layer completely and there is no change in thickness increase With the increase of the dipping time when the addition of aluminum has been changed until $60 \mathrm{Sec}$. This means that the growth rate of the interstitial layer which is affect in the thickness increase proportional directly to the ratio of the aluminum additives, while in the period $(60$ - 360) observed increase in galvanize layer with a small increase in the pure zinc layer as shown in Figure (9) which represents the relationship between dipping time (ratios different of $\mathrm{Al}$ additive) and total thickness of galvanize layer. Found that effect added to increase the thickness of the galvanize layer appeared at periods of time $(240-600 \mathrm{sec})$ and the effect was increased by $(5.5 \% \mathrm{Al})$. The increase in dipping time gave a good chance for the growth of the interlayer whether adjacent to the surface of the steel, usually with the aluminum ternary alloy (Al-Fe-Zn), and the developing layer of molten freeze made up of zinc and added aluminum and other elements (lead and residual metal residues from Figure8.

zinc purification), which may also be a ternary alloy of (Al-Zn$\mathrm{Pb}$ ), and the more time dipping in the molten increased the tem- 
perature of the sample reaches up to a degree close to the molten and thus helped to grow and be a thick layer free of defects [14]

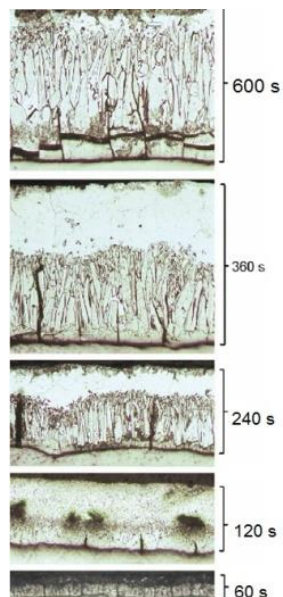

Fig.8: shows the thickness of galvanize layer

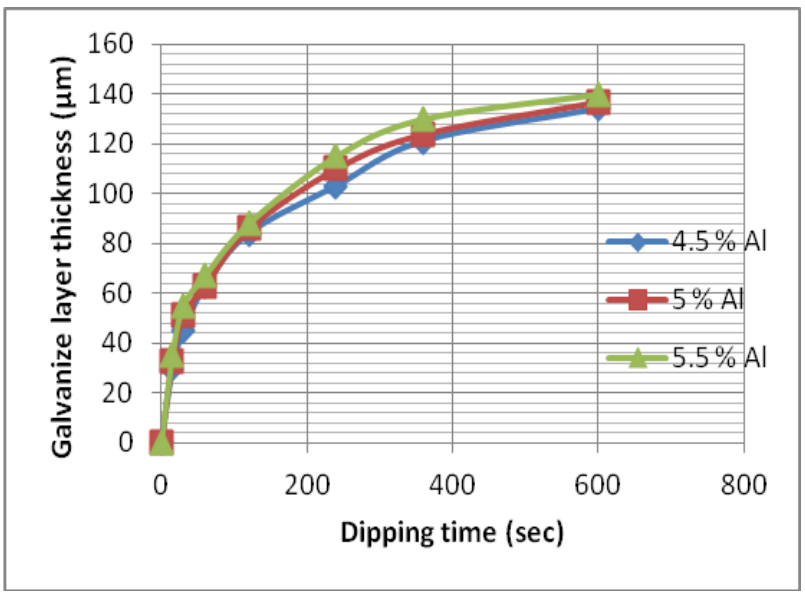

Fig.9: shows the relationship between dipping times in zinc molten and the layer of galvanized

Figure (12-11-10) shows the relationship between the bending angle and the bending curve produced for $(4.5 \%, 5 \%, 5.5 \% \mathrm{Al})$ and for different time periods of the galvanized. Observed as in figure (10) no effect on the thickness of galvanize layer at period times (15-60 sec.).Effect of the addition was increased when the dipping time was increased and the moment of the bending (bending resistance) increased as the angle of bending,

Addition ratio and dipping time increased.

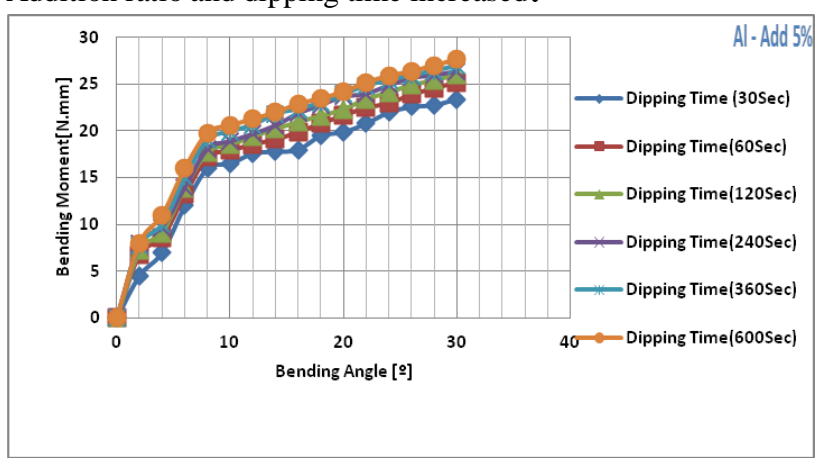

Fig.11: Relationship between bend angle and bending curve (for samples with $\mathrm{Al} 5 \%$ addition)

Figures(11-12) showed similar behavior. However, the increase in the ratio of the addition of the aluminum caused an increase in the bending value when the bending angle was increased by more than $15^{\circ}$ due to the increased thickness of the adhesion layer of the steel and the interlayer because the increase lead to increase the galvanize resistance to bending moment [15]. Samples with (Al-5.5\% addition) showed the cracking behavior and the nature of the breakage in the galvanize layer with increasing dipping time in the molten as observed in Figs. (13, $14,15,16,17,18)$ the cracks are formed in the adhesion layer of steel and grow towards the interstellar layer until it reaches the surface layer and whenever the interstellar layer thicker increase the longitudinal cracks in the adhesion and leading to the separation of galvanize layer as showed in Figures $(13,14,15)$, the increase in longitudinal and transverse cracks in the interstellar layer and its growth towards the surface layer leads to a breakage in the total galvanize layer and the breakage of the galvanize layer at the bending angle $\left(30^{\circ}\right)$ were appeared due to the shear stress between the cracks in the thick interstitial layer due to bending [16], as shown in figures $(16,17,18$

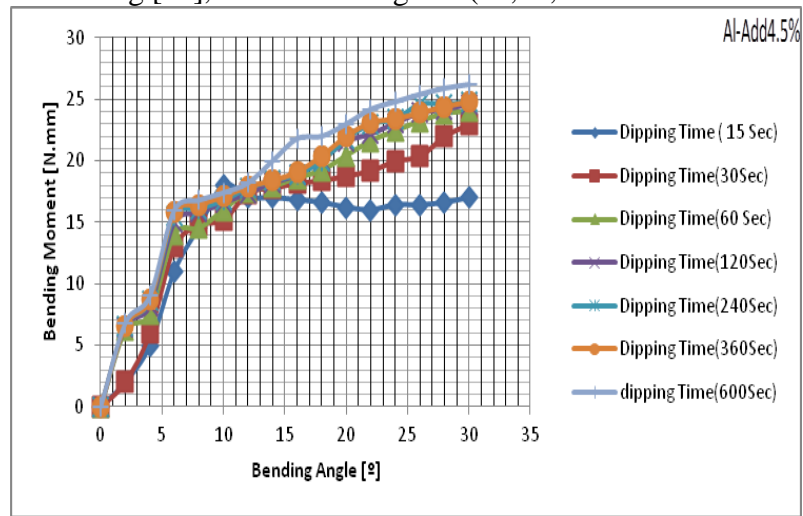

Fig 10: Relationship between bend angle and bending curve (for samples with $4.5 \%$ addition

Figure (19) shows the relationship between the hardness (HV) and the time of exposure to erosion of the galvanize samples with addition ratios $(4.5 \%, 5 \%, 5.5 \% \mathrm{Al})$. observed that the change few in the hardness of the samples at the time of exposure to the limit of (10000 s) in the presence of Thickness galvanize layer at the beginning of time When more than (10000 s) is passed, the value of hardness is increased due to the removal of the layers of galvanize to reach the highest hardness value, which represents the hardness of the steel. It was noted that the minimum addition (Al-4.5\%) is slightly stronger than other samples this is due to the low thickness of the galvanize layer in it. This indicates that erosion resistance is associated with and is strongly affected by the thickness of the total galvanize layer, especially the layer Adjacent to the surface of the steel as shown

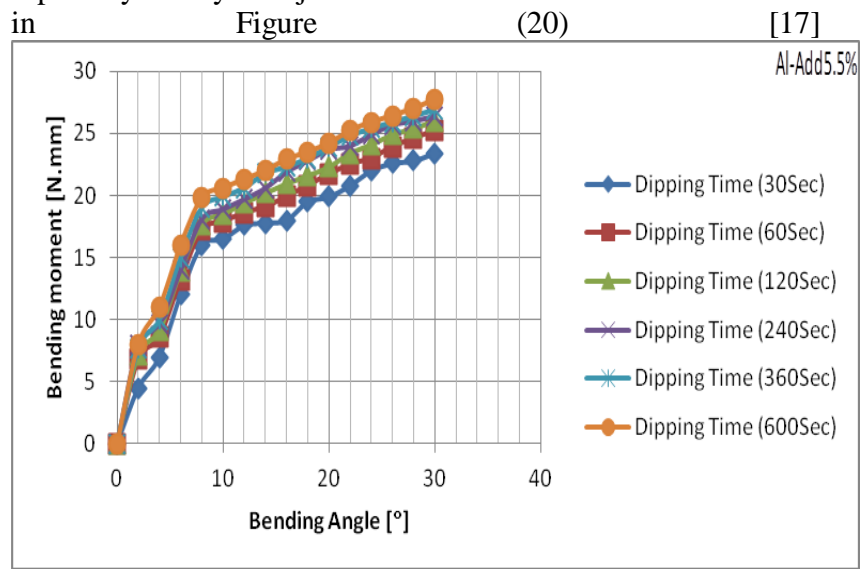

Fig.12:Relationship between bend angle and bending curve (for samples with $5.5 \%$ addition rate 


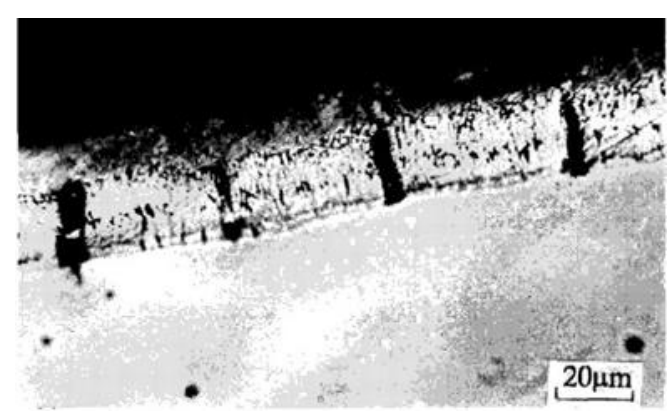

Fig.13: cracks (in the sample (al-5.5\%) at the time (60 s)

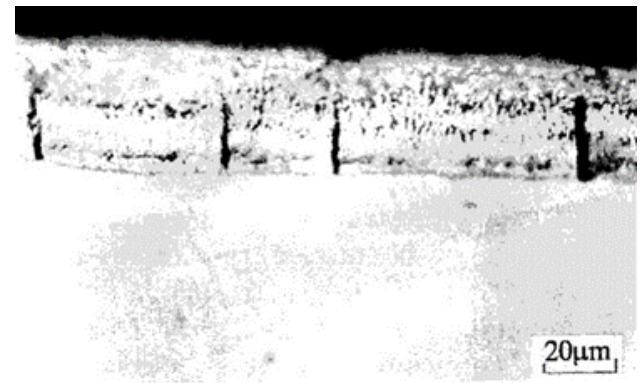

Fig.14: cracks (in the sample (Al-5.5\%) at the time (30 s)

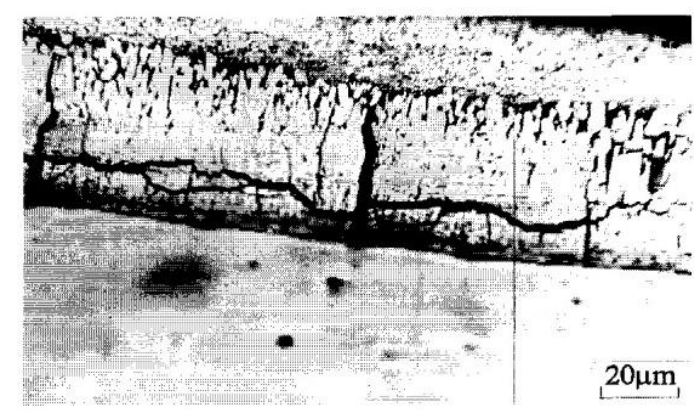

Fig.15: cracks (in the sample (al-5.5\%) at the time (240 s)

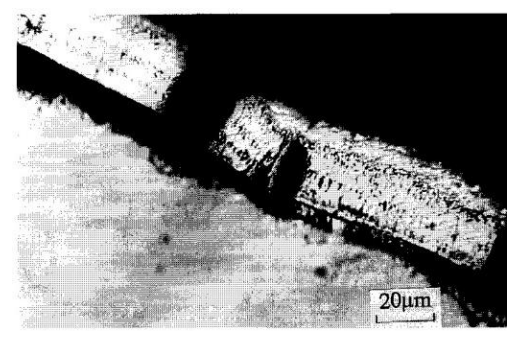

Fig.16: cracks (in the sample (al-5.5\%) at the time (120 s )

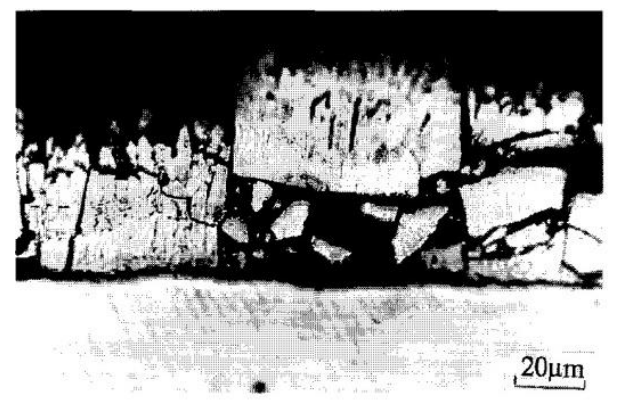

Fig.17: cracks (in the sample (al-5.5\%) at the time (600 s)

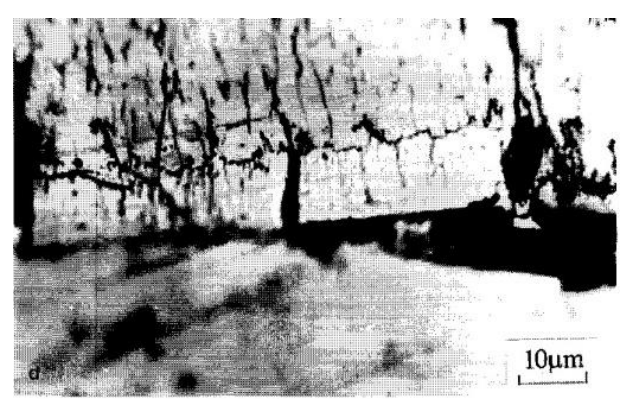

Fig.18: cracks (in the sample (al-5.5\%) at the time (360 s)

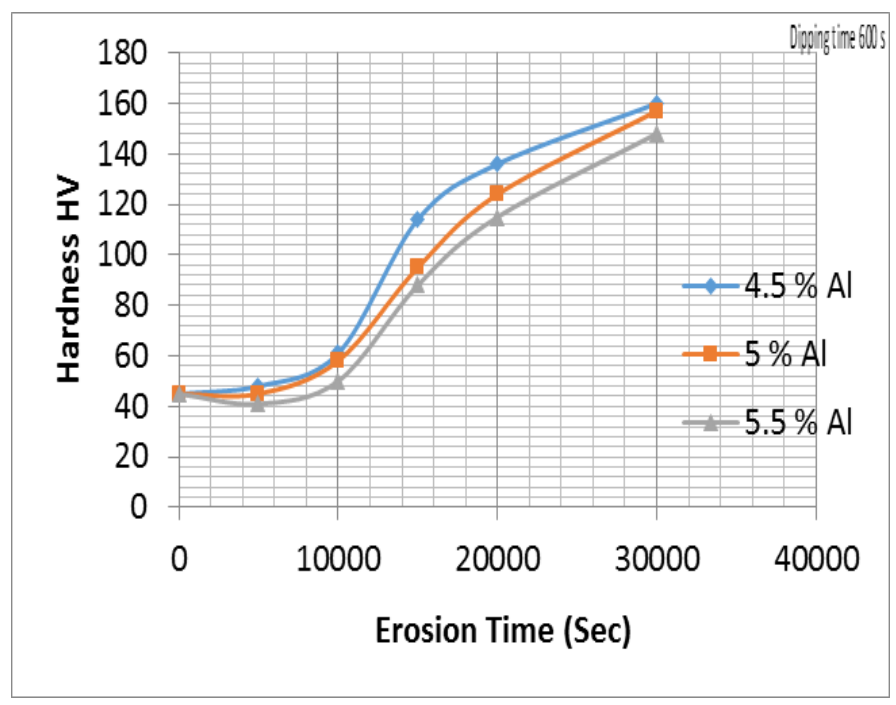

Fig.19: hardness (hv) in samples (al-5.5\%, 5\%, 4.5\%) at dipping time in molten (600s)

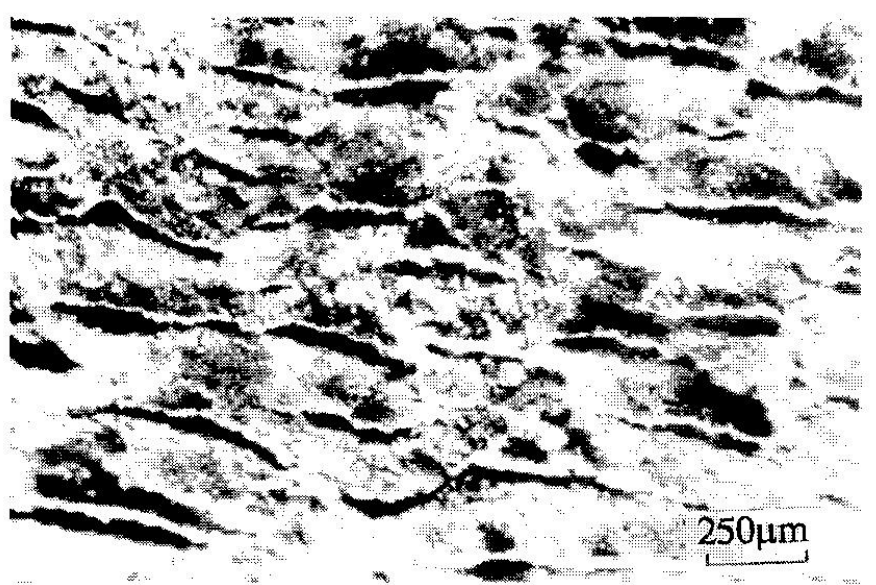

Fig.20: effect of erosion on sample surface (in sample (al-5.5\%) at dipping time in fused $(600 \mathrm{~s}))($

\section{Conclusions}

1-The thickness of the galvanize layer increases as the dipping time increases in molten and the addition of aluminum increases.

2- Aluminum is a ternary alloy with iron and zinc ( $\mathrm{Fe}-\mathrm{Zn}-\mathrm{Al})$ to form the adjacent layer, which increase thickness as increase the dipping time in the molten and The addition of aluminum and has helped the growth of the important inter- 
stitial layer to increase the thickness of the total galvanize layer.

The bending angle affecting the galvanize layer starts from the angle $\left(15^{\circ}\right)$ to the maximum angle $\left(30^{\circ}\right)$. 3 -

4- Increasing the thickness of the interlayer increases the erosion resistance and bending resistance.

\section{References}

[1] SorensenP.A, Kiil S, Dam-Johanse K, Weinell C.E, "Anticorrosive coatings: a review", J.Coat. Techn. \& Res. 2009.6: 135-176.

[2] Natali S, Volpe V, Zortea L, Burattini C, Di Cocco V, Iacoviello F." Mechanical and structural characterization of $\mathrm{Zn}-\mathrm{Ti}$ colored coatings", Procedia Engineering . 2015.109: 105- 112.

[3] Ping Wu,* Hong Mei Jin, and Hong Lin Liu, "Investigation of Additive Effects on Zn Diffusion in Hot-Dip Galvanizing by DFT Calculations", Chem. Mater. 2002.14: 832-837

[4] Tzimas, E., Papadimitrou, G. "Cracking mechanisms in high temperature hot-dip galvanised coatings", Surface and Coatings Technology, 2001.145: 176-185.

[5] Peng Li, Han Chen* " Vibration Analysis of Steel Strip in Continuous Hot-Dip Galvanizing Process " Journal of Applied Mathematics and Physics, 2013.1: 31-36

[6] Kinstler T.J, "Current Knowledge of the Cracking of Steels during Galvanizaton," Galva Science LLC, AISC, 2005.

[7] Roger J, Bosselet F, Viala J.C, X-rays structural analysis and thermal stability studies of the ternary compound alpha-AlFeSi, J. Solid State Chem.. 2011. (184).

[8] Phelan D, B.J. Xu, Dippenaar R, Formation of intermetallic phases on 55wt.\% Al-Zn-Si hot dip strip, Mater. Sci. Eng. A, 2006. 420:144-149.

[9] udd W.J and Wen S.W, "Failure Mechanisms during Galvanization," 2008.121-123

[10] Hong Mei Jin and Yi Li," Study on the Behavior of Additives in Steel Hot-Dip Galvanizing by DFT Calculations " , Chem. Mater. 2000.12: 1879-1883.

[11] Hong Mei Jin and Yi Li," prediction of new additives for galvanizing process by the properties of their constituent chemical element" , Journal of materials research . 1999.14(5):1791- 1795.

[12] Scott T. Bluni,A. R. Marder, and J. I. Goldstein , "Surface characterization of hot -dip galvanize coatings ", Materials Characterization. 1994 . 33:93-97.

[13] ASTM Standard , ASTM E399 "Safeguarding against Embrittlement of Hot-Dip Galvanized Structural Steel Products and rocedure for Detecting Embrittlement," ASTM International, West Conshohocken, 2007.

[14] Radka Pernicovaa, Daniel Dobiasa, Petr Pokornya "Problems connected with use of hot-dip galvanized reinforcement in concrete elements"Procedia Engineering 172 ( 2017 ) 859 - 866

[15] Marder A.R, "The metallurgy of zinc - coated steel", Progress in Materials Science (2000).45: 191-271.

[16] Sung- Ryong Kim, John A. Nairn,"Fracture mechanics analysis of coating/substrate systems Part II: Experiments in bending ", Engineering Fracture Mechanics2000.65: 595- 607.

[17] Szabadi L, Kalácska G, Pék L, Pálinkás I," Abrasive Wear of Different Hot-Dip Galvanized

Multilayers ", Sustainable Construction and Design , 2011. 82-92. 